Book review

\title{
The politics of public health in the United States
}

\author{
Kant Patel, Mark E. Rushefsky \\ Armonk (NY), London, England: M.E. Sharpe, 2006, \\ pp. 346, \\ ISBN $075651135 X$ (hardcover), 0765611368 (pbk)
}

This book is a historical and political analysis of the public health system in the United States since 1798. A major part of the analysis is aimed at the relationship between the development of the public health system and that of private medicine. The conclusion is that this relationship influences the politics of public health still today, in terms of a sharp division and a lack of integration between the two.

After a general introduction, the book concentrates on seven specific issues: leadership, relation of public health with private medicine, with law, with science, with genetics, with environment, and with bioterrorism. Each of the chapters gives a description and analysis of the history of the politics of public health and these specific issues.

As in many other western countries, the reason for the reappraisal of the public health system was the 2000 WHO yearly report in which it was stated that although the US has the highest overall health expenditure, they scored only $37^{\text {th }}$ on the index for overall health system performance. Based on recent reports and publications, the authors attribute much of this poor performance to a failing public health system. It is stated that 'at the beginning of the twenty-first century, the American public health system resembled a hodgepodge of programs and agencies rather than a coherent system.' (p. 19) 'The American public health system did not arise out of planning efforts, but like most things in this country, it grew piecemeal, in response to events, politics and perceptions' (p. 278).

The authors see three main reasons for this situation.

1. The very expensive, but not population-wide, private health care system undermines the possibilities of the public health system by draining public health funding and workforce.

2. There is constant friction between individual and civil liberties on the one hand and public welfare on the other. Public health is more difficult because of the general American distrust of government laws and regulations.
3. The government lacks the capacity for conducting regular evaluations of the public health infrastructure.

Regarding the relationship between health care and public health the authors argue that: 'The history of the relationship between private medicine and public health in the US can best be characterized as history of cooperation, apprehension, conflict, and at times open hostility' (p. 40). 'There is a deep, historically grown, gap between private medicine and public health. This gap is persistent because of the financial and economic interests of health care professionals, insurance companies and health care providers. Programs as Medicaid and Medicare are further sustaining this gap because - partial - public funding of health care drains money from the public health system' (p. 72).

In their analysis, the authors see the following developments for the future and suggestions for solutions:

1. Cost considerations are forcing consolidation and creation of integrated systems of care. Managed care is also forcing medicine to become more active in traditional public health areas. The push for practice guidelines is forcing medicine to incorporate data sets. Terrorist attacks and anthrax attacks have raised the spectre of potential bioterrorism attacks. This has focused attention on the need for strong collaboration between medicine and public health to effectively deal with such an attack (p. 100).

2. If we understand politics as involving conflicts of interests and values, then public health finds itself in the middle of politics. All of these involve value conflicts and require behavioural changes. Some affect industries in fairly drastic ways. Public Health officials are often not the ones making the final decisions, but they can place these kinds of issues on the political agenda, lobby for them, and carry them out (p. 283).

3. The authors are enthusiastic about small scale initiatives of cooperation between health care and public health. They refer in this respect to the Pocket Guide to cases of Medicine and Public Health collaboration: http://www.cacsh.org/ mphguide.html (p. 94). 
Patel and Rushefsky cite Mullan in a rather desperate conclusion:

This may require public health officials and practitioners to be idealist like Don Quixote, pragmatic cynics like Machiavelli's Prince, and willing to ambush the public conscience and budget like Robin Hood to fulfil its mission of preventing disease and promoting public health' [Mullan, Am. J. of PH 90 (2000) p. 702-6].

This book is surely strong in its historical overview and political analysis. Its weak points are a lack of insight in theprofessional content of public health and a rather poor set of solutions for the analysed problems. The latter could have been prevented by choosing a more international perspective and by making the analysis more comparative with other western countries.

But for everyone who is interested in the history of public health in the US, especially in the difficult relationship between health care and public health in America, this book gives a lot of food for thought.

Jac Drewes

E-mail: j.b.drewes@chello.nl 